DOI: 10.20472/IAC.2017.029.017

\author{
DILEK KILIÇ \\ Hacettepe University, Turkey
}

SELCEN ÖZTÜRK

Hacettepe University, Turkey

ISMAIL ÇAKMAK

Hacettepe University, Turkey

\title{
INVESTIGATING A SOCIAL PHENOMENON: EQUITY IN HEALTH CARE UTILIZATION-THE CASE OF TURKEY
}

\begin{abstract}
:
Equity in the use of health care services is an issue which has increasingly been on the health policy agenda in recent years in both middle and low income countries. In recent years, empirical research in equity in health care utilization employs Andersen (1968)'s behavioural model. This study employs the probit model and uses 2008, 2010 and 2012 "Health Survey" data for Turkey in order to investigate the concept of equity in health care utilization in Turkey. This study analysis equity in health care utilization in GP, specialist and inpatient visits. Andersen's behavioural model identifies 3 factors for health care utilization, namely; predisposing, enabling and need factors. Predisposing factors include; sex, age, education, marital status and employment status. Enabling factors include; location of residence (urban/rural), insurance status and income level. Finally need factors include; perceived and assessed health status of the individual. The results indicate that the need variable has the highest marginal effect in health care utilization in Turkey. Such result suggest that need is an important factor in health care utilization and let us conclude that the health care system in Turkey is equitable. Furthermore, since insurance status has the second biggest marginal effect we conclude that enabling factors are more important than predisposing factors in Turkish health care system.
\end{abstract}

\section{Keywords:}

Health Behaviour, Health and Inequality, Equity

JEL Classification: D63, I12, I14 